\title{
Una aproximación a la figura del arquitecto asturiano Francisco García Nava (1868-1937)
}

\author{
Ángel Leal Serrano. \\ Máster de Estudios Avanzados en Historia del Arte Español. \\ U. Complutense de Madrid
}

RESUMEN:

El arquitecto Francisco García Nava es conocido por ser el autor de la Necrópolis del Este de Madrid, pero ahí no acaba su obra. Lo poco que se ha escrito sobre él contiene errores de datación y autoría. El presente artículo pretende dar a conocer mejor a este arquitecto, clarificar datos, señalar la amistad y colaboración con el también arquitecto, Emilio Fernández-Peña y fijar la autoría de los distintos trabajos que se le han atribuido. También presentamos un panteón como posible obra suya.

PALABRAS CLAVE:

arquitecto, autoría, Asturias, Francisco García Nava, Emilio Fernández-Peña.

\section{ABSTRACT:}

Architect Francisco García Nava is known for being the author of The Necrópolis East Madrid. His work does no end here. So little has been written about him it contains dating and authorship errors. This article aims to better meet this architect, clarify dat, also seeks to highlight the friendship and collaboration with another architect Emilio Fernández Peña , and above all, clarify the authorship of the different works which have been attributed to him. A pantheon is also presented as his possible work.

KEY WORDS:

architect, authorship, Asturias, Francisco García Nava, Emilio Fernández-Peña. 
La figura de Francisco García Nava no ha sido prácticamente estudiada. La escasa historiografía así lo demuestra. Consideramos que ya es momento de reivindicar el trabajo de este arquitecto ${ }^{1}$. Como dice Carlos Saguar, "La trayectoria artística de Francisco García Nava merece una monografía rigurosa y profunda que le sitúe en el alto lugar que le corresponde y que hasta la fecha, incomprensiblemente, no se le ha reconocido" 2 .

Básicamente, García Nava es conocido por su actuación en la Necrópolis del Este (Av. de Daroca, 96, Madrid). No en balde le ocupó 22 años de su vida. José Ramón Alonso Pereira ha apuntado que se trata de "una obra que posiblemente sea la más genuina aportación que puede hacer Madrid al conjunto modernista internacional" 3.

En general, en su obra García Nava "desarrolló un particular lenguaje arquitectónico, reinterpretando y superando con talento todas las corrientes vigentes del eclecticismo mimético, desde el historicismo medievalista hasta el neomudéjar, para gestar un imaginativo modernismo con un fuerte componente secesionista" ${ }^{4}$. A esto hay que añadir la influencia gaudiana (la cúpula de la capilla y el remate de la torre adosada en la Necrópolis del Este ...).

Abordó diferentes tipos de edificios según su uso: religioso (cementerio, panteones e iglesias); residencial ${ }^{5}$ y otros usos (educativo y ocio).

Fue premiado en dos ocasiones. La Junta de la Exposición Internacional de Higiene (Dresde, 1911) le concede un diploma de honor por su colaboración científica (Fuente familia García-Nava). Y el Ayuntamiento de Madrid, por el diseño de la casa higiénica del Camino de la Dehesa de la Villa $(A B C$, año IX, no 3113 del 23/12/1913, p. 6).

2 SAGUAR QUER, Carlos.: Arquitectura funeraria madrileña del s. XIX. Tesis. Universidad Complutense, Madrid, 1989, p. 338.

3 ALONSO PEREIRA, José Ramón.: Madrid 1898-1931 de Corte a Metrópoli. Consejería de Cultura y Deportes-Comunidad de Madrid, Madrid, 1985, p. 73.

4 ROCHA ARANDA, Óscar da.: El Modernismo en la Arquitectura madrileña. Génesis y desarrollo de una opción ecléctica. CSIC, Madrid, 2009, p. 298.

5 Algunas viviendas carecen de interés artístico al ser modestas, con un simple valor funcional. Un ejemplo de este tipo lo encontramos en el Paseo del Cisne, 13 y 15 -actualmente Calle Eduardo Dato- en Madrid. El propio arquitecto, al final de la memoria descriptiva, señala: "Los adjuntos planos dan idea de esta pequeña construcción que no ofrece particularidad alguna fuera de la construcción vulgar”. Fuente: AVM. Signatura 12$259^{*}-35$.
Suele combinar el ladrillo con la piedra blanca, utilizando el granito para el zócalo. Así lo podemos apreciar en algunas obras esenciales (Cementerio de la Almudena, Iglesia de la Buena Dicha en Madrid ...)

Queremos, con el presente trabajo, contribuir a dar a conocer quién fue y esclarecer aquellos errores de datación y autoría ${ }^{6}$.

\section{Una fecha de nacimiento problemática ${ }^{7}$}

Sin duda alguna Francisco García Nava, denominado por algunos "arquitecto de cementerios", nació en Somió -actualmente zona residencial de Gijón (Asturias)-, un 12 de mayo. Lo que es más problemático, en un principio, es delimitar el año, ya que se barajan dos fechas. En el Archivo de la Villa de Madrid podemos comprobar que, tanto la Hoja de Padrón ${ }^{8}$ de 1930 como la Hoja de Servicios ${ }^{9}$ de su trabajo en el Ayuntamiento de Madrid -documentos cumplimentados por el propio García Nava-, nos indican que su año de nacimiento es el de 1872. Por otra parte, en el Archivo General de la Administración ${ }^{10}$ se halla el expediente de sus estudios de Arquitectura y una copia manuscrita de su acta de bautismo. En esta ocasión el año que aparece es 1868.

No se encuentra inscrito en el libro de nacimientos (1817-1868) existente en el Archivo Municipal de Gijón ni en el Registro Civil en funcionamiento desde 1871. La respuesta se halló en el Archivo Histórico Diocesano de Oviedo ${ }^{11}$ :

En doce mayo mil ochocientos sesenta y ocho yo infrascrito Cura párroco de Somió, en el obispado de Oviedo, arciprestazgo de Gijón, bauticé solemnemente á un niño que nació el mismo dia y á quien ha sido puesto el nombre de Francisco Domingo, hijo legitimo y de legitimo matrimonio de D. Andres Garcia, natural de Granda, y de Da. Isidora Nava, de Gijón ...12

$6 \quad$ No se va a tratar su obra en Madrid, excepto el edificio de la calle Casado del Alisal por ser éste inédito. Se presentará al final del artículo una bibliografía sobre su obra madrileña.

$7 \quad$ El año citado por los estudiosos ha sido el de 1877.

8 AVM. Hoja no 4499 del Empadronamiento Municipal de diciembre de 1930.

9 AVM. Signatura 30-398-4.

10 AGA. Referencia: IDD(05)001.027, sig caja 31/14813, exp. 30.

11 AHDO. Actas bautismales 20.23.6, folio 150.

12 Transcripción literal con la ortografía original. 
¿Por qué en los documentos tramitados "de puño y letra" por García Nava existe una diferencia de cuatro años menos respecto de su edad real? No se sabe.

\section{Estudios y formación}

Tenemos constancia de su paso por el Instituto Jovellanos de Gijón con motivo del otorgamiento de un diploma (31 de octubre de 1885), "por su buena conducta, aplicación y brillante aprovechamiento, durante el curso último, en la asignatura de dibujo lineal y de adorno" ${ }^{13}$.

Lo encontramos ya en Madrid en 1891 trabajando en el Ayuntamiento como Auxiliar de Secretaría. En el curso académico 1892-93 compagina el trabajo con los estudios de Arquitectura en la Escuela Superior de Madrid. Permuta su plaza en la Secretaría por la de Delineante-Escribiente de Cementerios en septiembre de 1893 y continúa con sus estudios.

García Nava concurre a unas oposiciones -de las que hablaremos más adelante-, presentando su currículum ${ }^{14}$. De esta manera conocemos que entre los años 1894 y 1895 estuvo de ayudante del arquitecto municipal madrileño, José López Sallaberry. Y que a partir de 1895 pasó a las órdenes del también arquitecto municipal, Pedro Domínguez. Quizás este sea el motivo de abandono momentáneo de la Universidad durante los cursos 1895-1896 y 1896-97.

Vuelve en el curso 1897-98 a Arquitectura, realizando seis asignaturas, el año con mayor número de materias cursadas, y lo más sorprendente, es que lo va a simultanear con los estudios de Ciencias en la Universidad Central de Madrid. Al final sólo realiza una asignatura de Ciencias: Mecánica Racional ${ }^{15}$. Además, continúa trabajando. Nuevo año sabático en los estudios en el curso 1898-99. Finalmente, se olvida de las Ciencias y tras los cursos 18991900, 1900-01 y 1901-02 obtiene el título de arquitecto el 25 de noviembre de 1902.

13 Archivo de la familia García-Nava. En 1928 Francisco García Nava solicita la unión de los dos apellidos, en uno solo, para sus descendientes (BOPO, nº 38 del 16 de febrero).

14 El Lábaro. Diario independiente, año VIII, $\mathrm{n}^{\circ} 2.172$, 23/4/1904, p. 2.

15 AHN. Signatura UNIVERSIDADES, 5605, Exp. 17.

\section{Aspirando a una plaza de arquitecto}

61

El año 1904 pudo marcar un cambio radical en su vida. A través de los periódicos salmantinos de la época conocemos la candidatura de García Nava a una plaza vacante de arquitecto municipal en el Ayuntamiento de Salamanca. A tal concurso se presentan once aspirantes. Tres de ellos son excluidos “...por no acompañar a sus instancias los documentos pedidos en la convocatoria". ${ }^{16}$

En la sesión del Pleno del 25 de abril de 1904 se procede a la votación ${ }^{17}$ para cubrir el puesto. El resultado de la misma es el que sigue:
D. Francisco García Nava (10 votos).
D. Santiago Madrigal y Rodríguez (9 votos).
D. Antonio Zumárraga (2 votos).
D. Martín Sureda Vila (1 voto).

Se decide, entonces, repetir la votación entre los dos candidatos más votados. El resultado fue de 11 votos cada uno. Ante el empate, se procedió a un sorteo y "La Providencia proclamó nombrado Arquitecto municipal al designado por la suerte, D. Santiago Madrigal y Rodríguez". ${ }^{18}$

No consiguió el trabajo, pero unos meses después, en enero de 1905, es nombrado arquitecto de cementerios en el Ayuntamiento de Madrid.

\section{Amistad, colaboración y autoría}

Francisco García Nava mantuvo una fuerte amistad con otro arquitecto asturiano, Emilio Fernández-Peña Villa (1873-1955) ${ }^{19}$, titula$\mathrm{do}^{20}$ dos años más tarde, es decir, en 1904. No sólo se encontrarían en la Escuela Superior de Arquitectura, sino que en el curso 1897-1898 coinciden en la clase de Mecánica Racional en la Facultad de Ciencias.

\footnotetext{
16 El Adelanto. Diario de Salamanca, año XX, nº 6.109, 26/4/1904, p. 1.

17 El Porvenir. Diario republicano, 25/4/1904, p. 3; El Castellano, año II, n 119, 28/4/1904, p. 2; El Lábaro. Diario independiente, año VIII, $n^{\circ} 2.174,26 / 4 / 1904$, p.2.

18 AMS. Registro de actas de Sesiones de 1904, signatura 3120/277, folio 47.

19 Para el año de nacimiento SHCOAM. Ref. 8.051. Año de defunción, $A B C$ del 28/10/1955, p. 53.

20 AGUCM. Referencia TIT-12.
} 
Según Alonso Pereira, estos arquitectos fueron ...

(...) autores de las casas ovetenses en Santa Cruz vuelta con Cabo Noval, en Uría 46-48, o en Covadonga 29 (todas de 1911), del proyecto de Caja de Ahorros para Gijón (1913, no ejecutado), o de la casa de la calle San Francisco de Avilés (1916); culminando en Asturias la obra de García Nava en el soberbio pabellón funerario de Gabino Álvarez en Somado. ${ }^{21}$

Se consultó el archivo de la familia García-Nava y pudimos comprobar la existencia de planos sin firmar de algunas de las obras mencionadas (casas de las calles Marqués de Santa Cruz, Covadonga o el panteón de Somado). También aparece el alzado de la vivienda de la calle Uría, 48 de Oviedo con la rúbrica de Fernández-Peña, no de García Nava, además de la del contratista y la del propietario.

Estos hallazgos dan más consistencia a la idea de colaboración entre estos arquitectos. Si nos ceñimos exclusivamente a la firma en los expedientes que custodia el Archivo Municipal de Oviedo, la casa de Marqués de Santa $\mathrm{Cruz}^{22}$ es de Emilio Fernández-Peña. Lo mismo sucede con la de la calle Covadonga ${ }^{23}$. Existen dos expedientes de la edificación de la calle Uría, 4446. El primero ${ }^{24}$ es de 1886. En él aparece la solicitud para construir una casa de nueva planta, así como los planos firmados por el arquitecto Juan Miguel de la Guardia. El segundo ${ }^{25}$ presenta la reforma de la fachada con arreglo al plano que se acompaña (1911). El arquitecto que lo firma es Fernández-Peña.

Especial atención requiere el expediente del edificio de Uría, $48^{26}$. Contiene el oficio de don Godofredo González-Río Conde al Ayuntamiento de Oviedo donde se expone el deseo de construcción de un edificio bajo la dirección del arquitecto Emilio Fernández-Peña (24 de agosto de 1910). No se adjunta planos. En cambio, se incluye una reclamación (30 de septiembre de 1911) de don Felipe Polo Flores contra la construcción de los salientes de la casa que, a su juicio, rebasa los límites que regulan las orde-

\footnotetext{
${ }_{21}$ ALONSO PEREIRA, J. R.: Historia General de la Arquitectura en Asturias. COAA, Oviedo, 1996, pp. 277-278.

nanzas municipales. La resolución del Ayuntamiento tiene lugar el 11 de abril de 1912. Todo esto, por lo visto, ha sido insuficiente para darle la autoría a este arquitecto. En la página web del Ayuntamiento podemos acceder al catálogo de edificios y comprobar que se le atribuye al arquitecto Juan Miguel de la Guardia. El argumento que se esgrime es que "sus caracteristicas formales y la construcción del edificio contiguo (núm. 46) por este arquitecto nos llevan a proponer para el núm. 48 la misma autoría. Entre las coincidencias estilisticas que presentan ambos edificios destacan el perfil ovalado del balcón del $2^{\circ}$ piso de la calle central del núm. 48 y el del $3^{\circ}$ del núm. 46" ${ }^{27}$. Pero se olvida un detalle esencial: Emilio Fernández-Peña sustituyó la fachada del ático original, que era de madera, por otro de obra de fábrica, según la reforma llevada a cabo en el edificio de la calle Uría, 46. De ahí, que el balcón del $3^{\circ}$ piso, que se cita, sea parte del proyecto. Por otro lado, como se ha dicho, existe un alzado de Uría, 48 (julio de 1910) en el que consta la firma de este arquitecto (Figs. 1-2) y que se corresponde perfectamente con la fachada real del edificio. Por todo ello, pensamos que no es Juan Miguel de la Guardia el autor, sino Emilio Fernández-Peña.

No existe duda en la autoría del proyecto para la Caja de Ahorros de Gijón. En las obras ${ }^{28}$ de la profesora Morales Saro se cita el expediente custodiado en el AMG. En él aparece el nombre de Francisco García Nava. El proyecto no se ejecutó por causas ajenas a la voluntad de su creador. El motivo real lo encontramos en los problemas de liquidez ${ }^{29}$ de la entidad por la supuesta mala gestión de su presidente y director-gerente, don Calixto de Rato y Roces. Hay que destacar el matiz social de esta fundación que en esas fechas había incluido entre

${ }_{27}$ http://www.oviedo.es/documents/12103/27862/599_ CAT.pdf (Consultado el 8/11/2014).

28 MORALES SARO, Ma Cruz.: Gijón 1890-1920. La arquitectura y su entorno. Ayuntamiento de Gijón, Gijón, 1978, pp. 62 y 70. MORALES SARO, Ma Cruz.: El Modernismo en Asturias. Arquitectura, escultura y artes decorativas. COAA, Oviedo, 1989, pp. 66 y 68.

29 El Pueblo Astur. Diario Social, año II, $\mathrm{n}^{\circ} 354$, 27/4/1914, p.1: Da la noticia de una posible suspensión de pagos. En el $n^{\circ} 355,28 / 4 / 1914$, p. 2: Se confirma la suspensión. En el no 361, 5/5/1914, p. 2: Interviene el Gobierno. En el no 422, 5/7/1914, p. 2: Apertura de la Caja de Ahorros. En este mismo diario del 18 al 28 de octubre de 1914, exceptuando el día 24, la Junta de Gobierno del Monte de Piedad y Caja de Ahorros de Gijón se dirige a su pueblo para explicarle la situación de la entidad y señalar al verdadero responsable. 

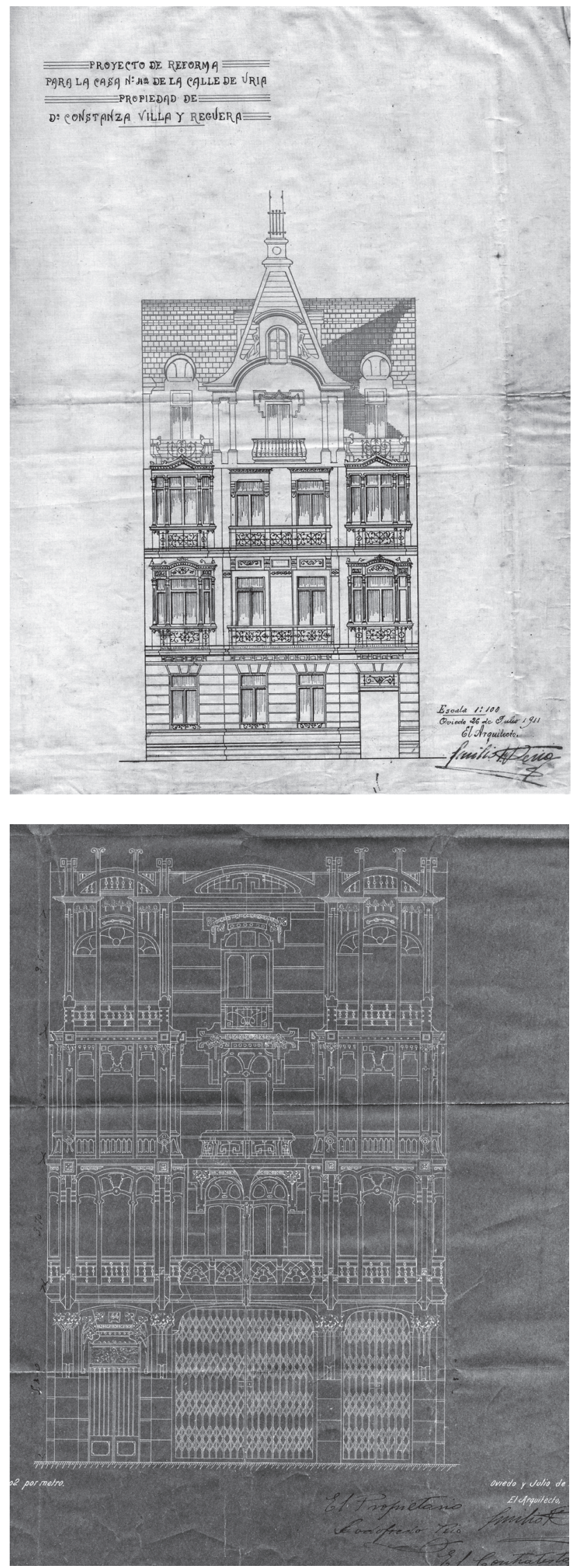

Fig. 1. Alzado de la casa de c/ Uría, 46-44 (Oviedo). Fuente: AMO.

Fig. 2. Alzado de la casa c/ Uría, 48 (Oviedo). Fuente: Archivo de la familia García-Nava. 
sus prestaciones la sanitaria, haciendo especial hincapié en los problemas alimentarios de los lactantes (Gota de Leche) y que, de haberse llevado a cabo, hubiese sido una de las instituciones pioneras de este tema en España.

Por el contrario, ha sido complicado recabar información de la casa de Avilés ${ }^{30}$ "debido a que durante la Guerra Civil se incendió parte del Archivo Municipal desapareciendo los expedientes de licencias de obras..." ${ }^{31}$. No obstante, existen dos catálogos: El Inventario de Bienes e Inmuebles Catalogados (IBIC), realizado por el Ayuntamiento de Avilés y el Inventario del Patrimonio Arquitectónico de Asturias (IPAA), elaborado por la Consejería de Cultura del Principado de Asturias. A continuación mostramos un esquema-resumen con datos de los edificios de la calle San Francisco donde, supuestamente, se ubica el edificio.

\begin{tabular}{|c|c|c|c|c|c|c|}
\hline \multicolumn{3}{|c|}{ I B I C } & \multicolumn{4}{c|}{ I P A A } \\
\hline $\mathrm{N}^{\circ} \mathrm{C} /$ & FICHA & ÉPOCA & ARQUIT & FICHA & ÉPOCA & ARQUIT \\
\hline 2 & 508 & 1890 & $?$ & $?$ & $?$ & $?$ \\
\hline 4 & 512 & 1900 & $?$ & AV-113 & 1911 & $\begin{array}{c}\text { A.ALONSO } \\
\text { JORGE }\end{array}$ \\
\hline 6 & 513 & 1910 & $?$ & $?$ & $?$ & $?$ \\
\hline 8 & 514 & 1890 & $?$ & $?$ & $?$ & $?$ \\
\hline 10 & 503 & 1916 & $\begin{array}{c}\text { M. DEL } \\
\text { BUSTO }\end{array}$ & AV-114 & 1901 & $\begin{array}{c}\text { M. DEL } \\
\end{array}$ \\
\hline $12-14$ & $504-505$ & 1900 & $?$ & AV-115 & H. 1915 & $?$ \\
\hline 16 & 506 & 1890 & $?$ & AV-116 & $1910-20$ & $?$ \\
\hline 18 & 507 & 1890 & $?$ & $?$ & $?$ & $?$ \\
\hline 20 & 509 & 1910 & $?$ & $?$ & $?$ & $?$ \\
\hline 22 & 510 & 1890 & $?$ & AV-117 & S. XIX & $?$ \\
\hline 24 & 511 & $?$ & $?$ & AV-117 & S. XIX & $?$ \\
\hline
\end{tabular}

A todo esto hay que añadir los datos que nos proporcionan los historiadores Juan Carlos y Vidal de la Madrid en su obra ${ }^{32}$ sobre las viviendas números 4, 6 y 8 proyectadas por el arquitecto Antonio Alonso Jorge.

Los edificios 12 y 14 son iguales. Su autor sería el maestro de obras, Armando Fernández Cueto, según testimonio oral de una descendiente $^{33}$ de éste. $Y$ lo corroboran dos publica-

30 La responsable del Archivo Municipal de Avilés nos confirmó que, de los expedientes conservados, no hay ninguno de García Nava y/o Fernández-Peña.

31 TORAL ALONSO, Elena.: "La arquitectura de Avilés en el s. XIX (1800-1914)" en AA.VV, El Patrimonio Artístico de Avilés. Casa Municipal de Cultura, Avilés, 1989, p. 91.

32 MADRID, Juan Carlos y Vidal de la.: Cuando Avilés construyó un teatro. Ediciones Trea, Gijón, 2002, pp. 196-199.

33 Se trata de su nieta, Matilde Benítez Fernández. Nos proporcionó información sobre las dos publicaciones que citamos. ciones. En La Semana Ilustrada ${ }^{34}$ aparece un artículo donde se comenta "otras obras hace Armando, de D. Eladio Muñiz, en la calle de la Ribera, de D. Ramón Valdés, D. Antonio Guardado, etc". Por otro lado, en Historia del palacio de Josefina Balsera ${ }^{35}$ se manifiesta que " $a$ principios de siglo en la calle La Canal, (hoy de San Francisco), se comienzan a derribar algunas casas situadas frente a la iglesia parroquial de San Nicolás, en cuyos solares se levantarán dos hermosos edificios propiedad de los señores Ramón Valdés y Antonio Guardado".

De los edificios que quedan sin verificación de autor, todos fueron realizados antes que comenzara el siglo XX, excepto uno: el número 16. Lo que más destacaríamos sería la combinación del ladrillo con la piedra blanca, algo bastante común en algunas obras madrileñas de García Nava, como ya se dijo. Los cuatro pilares de los soportales recuerdan caracteres gaudianos, tan del gusto de nuestro arquitecto. No obstante, no podemos asegurar esta autoría.

Si complicado fue el tema de la casa avilesina, muchísimo más fácil resultó, en teoría, conocer el autor del panteón de la familia de Gabino Álvarez en Somado. Prácticamente todos los estudiosos lo han identificado como de García Nava. Incluso, nosotros mismos habíamos pensado en ello por las siguientes razones:

- La existencia de un alzado sin firmar en el archivo de la familia García-Nava.

- La realización de dos panteones en el cementerio de Nuestra Señora de la Almudena o Necrópolis del Este (Madrid) y otros dos en el cementerio de San Isidro (Madrid).

- Encarnación Valdés, viuda de Gabino Álvarez, que había mandado construir el panteón de Somado, le encargó tres reformas importantes en su hotel de Madrid.

Por tanto, era lógico pensar en su autoría. Pero no fue obra de García Nava, sino de su amigo Fernández-Peña. Así consta en los planos que poseen los descendientes de Encarnación Valdés, y que la profesora Carmen Bermejo Lorenzo cita en su obra ${ }^{36}$. Lo curioso de la cons-

\footnotetext{
34 La Semana Ilustrada. Avilés, $\mathrm{n}^{\circ} 42,2^{\text {a }}$ época, 30/12/1900, s/p.

35 Historia del palacio de Josefina Balsera, Casa de don Mateo. Banco de Santander, Dpto de Comunicación Corporativa, 1987.

36 BERMEJO LORENZ0, Carmen.: "Arte y arquitectura funeraria de los emigrantes a América en Asturias. Siglos
} 
trucción del panteón es su ubicación. Se encuentra situado en el jardín de la casa. Gracias a las influencias de don Amando García Rubiera, familiar y capellán real, se consiguió la autorización oportuna. Éste se encuentra conviviendo ${ }^{37}$ (1915) con la familia de Encarnación en el hotel de la calle Marqués de Urquijo de Madrid.

Además de arquitecto, García Nava aparece como uno de los integrantes del Comité de Redacción de la revista Pequeñas Monografías de Arte $^{38}$. Escribió cinco artículos de diverso tipo:

- "Arista curva en una cubierta de hierro", no 9, enero 1908.

- "Cimentaciones en Nueva York", n ${ }^{11}$, marzo 1908.

- "Hotel de D. Valentín Sarasola en la villa de Grado (Asturias)”, n 19, junio 1909, dedicado a la obra de su compañero Peña. He aquí otra prueba de su amistad.

- "Conducción de agua derivada de una acequia”, no 23, octubre de 1909.

- "Comprobación de la estabilidad de una chimenea”, n 30, mayo 1910.

También en el archivo de la familia García-Nava encontramos una tarjeta de visita ${ }^{39} \mathrm{de}$ Fernández-Peña dirigida a su amigo.

Querido Paco: Lela avisa por telegrafo desde París que, mañana sabado nos espera para almorzar en ¿Toumiè? à la $1^{1 / 2}$.

Yo como sábado no ire à la obra por la mañana.

Tuyo

EMILIO FERNÁNDEZ-PEÑA

ARQUITECTO

TELÉFONO 51-84 M.

MAYOR, 92

XIX y XX", en Boletín del Real Instituto de Estudios Asturianos, año LV, no 157, Oviedo, enero-junio 2001, pp. 66-67.

37 AVM. Hoja no 137364 del Empadronamiento Municipal de diciembre de 1915.

38 BARJAU, Santi.: “Pequeñas Monografías de Arte (1907-1912), una revista artística española” en Locus Amoenus $\mathrm{n}^{\circ}$ 7, Barcelona, 2004, pp. 285-290. Artículo en el que podemos encontrar la historia de esta revista. Se puede consultar y bajar de la red: http://ddd. uab.es/pub/ locus/11359722n7p285.pdf (consultado el 25/5/2012).

39 Transcripción literal con la ortografía original.
Más detalles

65

Hablando de Inurria ${ }^{40}$, Ramón Montes Ruiz comenta que a comienzos de 1923 "le fueron encargados, por el arquitecto Emilio Fernández-Peña y Villa, dos figuras de temática religioso-funeraria para el Pórtico del Cementerio madrileño de Nuestra Señora de la Almudena".

Aún podemos añadir otro dato que afianzaría la relación de amistad y profesional: la existencia de un edificio en la calle Casado del Alisal, 12 de Madrid, proyectado, en principio, por los dos arquitectos. En el expediente de construcción ${ }^{41}$ comprobamos que se trata de edificar en un solar perteneciente a Peña. Observamos que la memoria descriptiva del proyecto $(23 \mathrm{de}$ diciembre de 1926) y el plano de alineación (18 de enero de 1927) están firmados por García Nava. Los planos de alzado, de la sección ABCD y de las diversas plantas son rubricados por los dos arquitectos (diciembre 1926). En el certificado de las pruebas efectuadas en el ascensor instalado (1930) aparecen los nombres de Fernández-Peña, arquitecto y de Jorge Balaguer, ingeniero industrial. Sin embargo, la firma de Fernández-Peña es sustituida por la de su amigo. El resultado final no fue el que se esperaba. Presentamos el alzado de la fachada que aparece en el expediente (Fig. 3) y el actual ${ }^{42}$ (Fig. 4). Se puede apreciar que no se parecen. No coinciden, ni siquiera, los huecos. Mientras que en el alzado primitivo nos encontramos con un edificio de características eclécticas, en la realidad observamos la tendencia hacia una arquitectura más depurada con formas geométricas simples y escasa decoración. La ornamentación la encontramos en la puerta de acceso y en el interior (vestíbulo y escalera) de estilo art déco. Desconocemos lo que originó el cambio. En la fachada aparece el nombre de Emilio Fernández-Peña y el año (1929). Se podría pensar que hubo una reforma intermedia que hubiese afectado de lleno a la portada, pero no fue así. En el año 2007 se presentó un proyecto de reforma que, al final, no fue realizado. Será en el

\footnotetext{
40 MONTES RUIZ, Ramón.: "Inurria. Biografía” en AA.VV, Mateo Inurria y la escultura de su tiempo. Ayuntamiento de Córdoba, Córdoba, 2007, pp. 462-463.

41 AVM. Signatura 27-218-25.

42 En el año 2007 se le encargó al arquitecto Ignacio Luengo una reforma. Este arquitecto realizó un estudio del edificio y entre los planos que realizó se encuentra el alzado del estado actual. Agradecemos a Ignacio Luengo el material facilitado.
} 


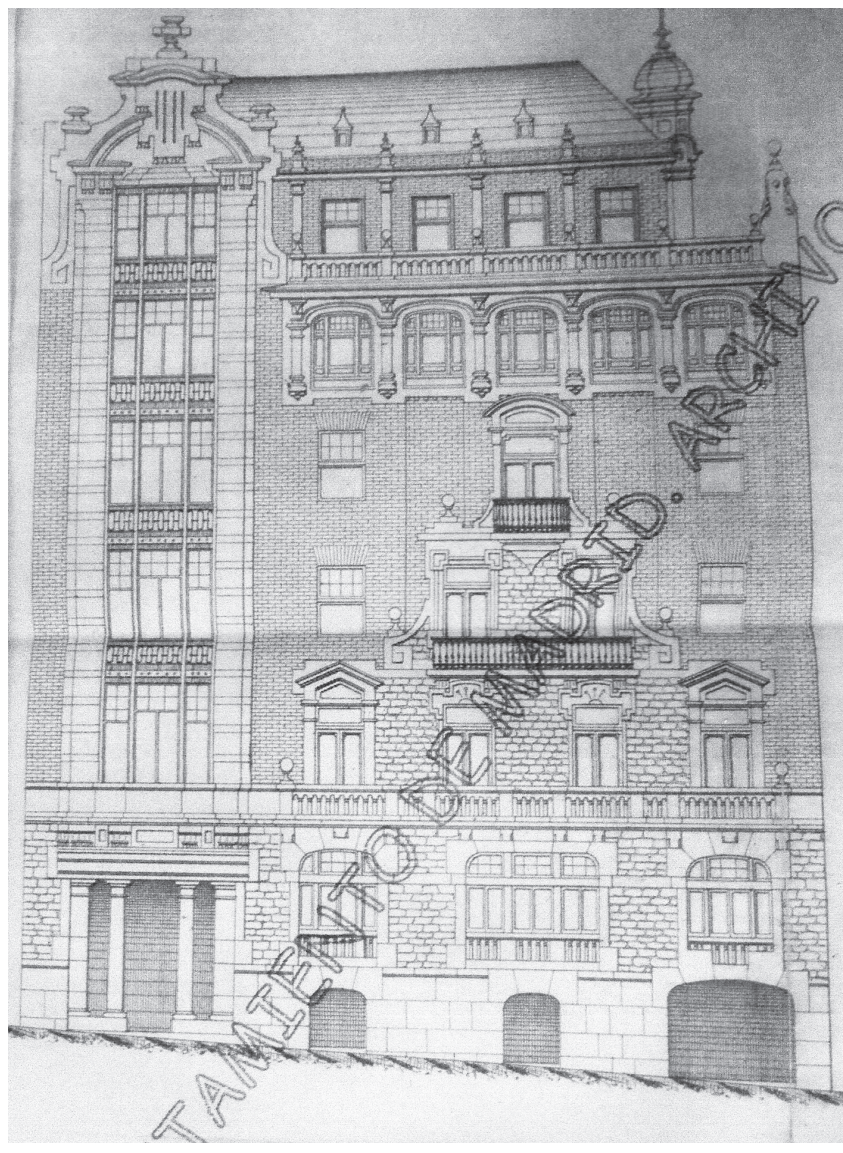

Fig. 3. Alzado de la fachada de Casado del Alisal, 12 (Madrid). Fuente: AVM.
2011 cuando se decida efectuar la restauración del edificio. La rehabilitación fue muy simple y no conllevó cambios estructurales. Hoy en día el edificio está incluido en el catálogo de elementos protegidos (fachada, puerta, vestíbulo y patio de luces) de Gerencia de Urbanismo ${ }^{43}$ del Ayuntamiento de Madrid.

\section{La jubilación}

El diario $A B C$ del 1 de marzo de 1936 publica la noticia de la próxima jubilación de los arquitectos municipales Sres. García Nava, Carrasco y Pfitz. Y termina apostillando: "Por lo visto, va a continuar la persecución” ${ }^{44}$.

Estamos a cuatro meses del comienzo de la Guerra Civil. El ambiente está bastante crispado. Pero esta situación no es nueva para García
Nava, ya que la lleva padeciendo desde hace tiempo.

En agosto de 1930 es nombrado arquitecto jefe de la sección de construcciones del Ayuntamiento de Madrid. Unos meses más tarde, en enero de 1931, se le incoa un expediente ${ }^{45}$ en virtud de la denuncia formulada por los Sres. Concejales D. Andrés Saborit y D. Eduardo Álvarez Herrero, en depuración de las causas que motivan las anormalidades ${ }^{46}$ en la Necrópolis del Este y las responsabilidades que pudieran derivarse. Serán casi tres años de diligencias para esclarecer la situación. Se tomó declaración a todo el personal de la Necrópolis, un total de 119 personas. También a algunos concejales y, por supuesto, a nuestro arquitecto.

El 6 de diciembre de 1933 García Nava es relevado de su cargo de Arquitecto Director de la Necrópolis del Este. Se le asignará, “dentro

\footnotetext{
45 AVM. Signatura 30-398-4.

46 Irregularidades. En todo el expediente se utiliza la palabra anormalidades.
} 


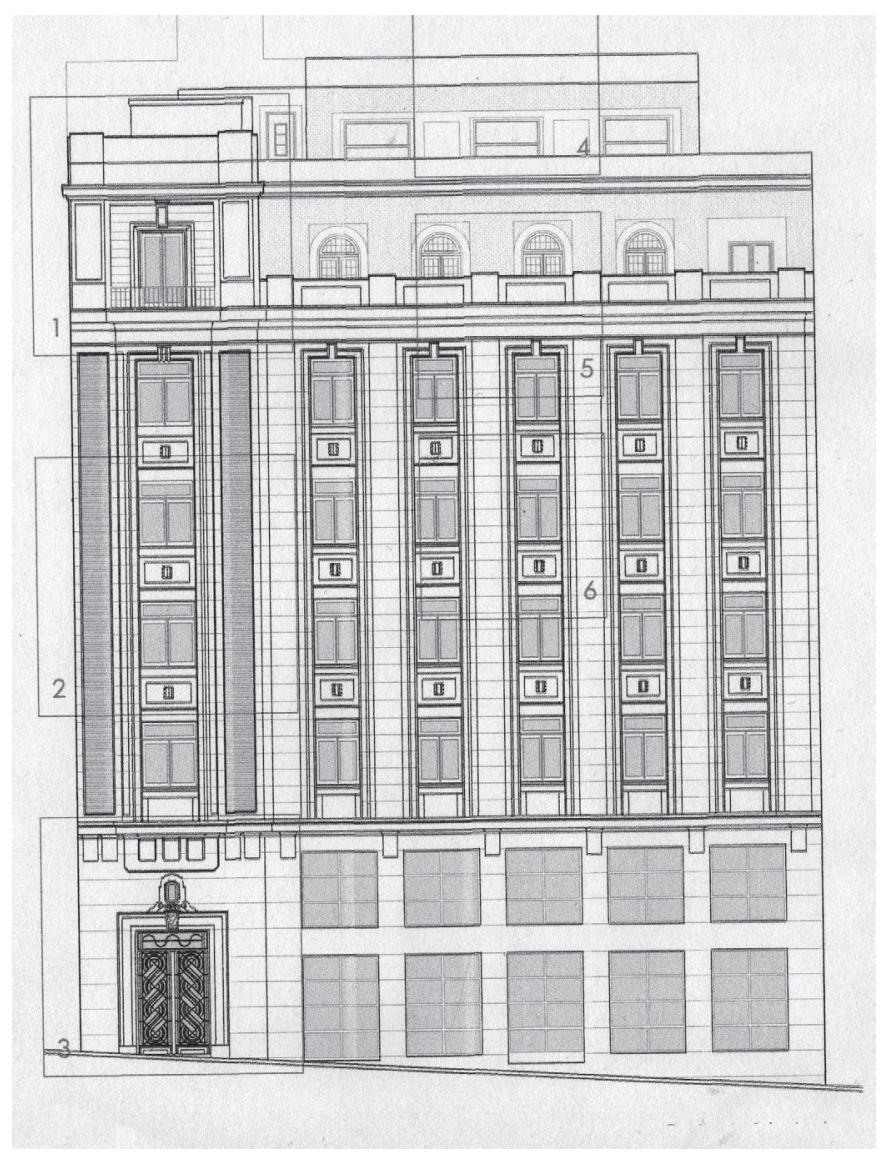

Fig. 4. Alzado de la fachada del edificio de C/ Casado del Alisal, 12 (Madrid). Fuente: Ignacio Luengo (2007).

del carácter técnico de su nombramiento, funciones de indole más secundarias" ${ }^{47}$

Como presintiendo un final cercano permaneció en el Ayuntamiento, pese al acoso, hasta el 14 de agosto de 1937, después de 45 años 9 meses y 7 días. Fallece el 29 de diciembre de ese mismo año ${ }^{48}$.

\section{La obra de García Nava en Asturias}

Es muy escasa, tan sólo dos obras: el ya mencionado proyecto para la Caja de Ahorros de Gijón y, en esta misma ciudad, la reforma de los edificios números 2-4 de la calle Pedro Duro y n ${ }^{\circ} 43$ de la calle Rodríguez San Pedro con fachada posterior a la de Marqués de San Esteban. La solicitud la presenta Arcadio de la Grana en representación de Margarita Rodríguez San Pedro. Se trata de "la estabilización

7 AVM. Signatura 30-398-4.

48 Tanto la fecha del cese como la fecha de defunción en AVM 40-491-28. de las fincas por refuerzo de sus cimentaciones $y$, segundo, el saneamiento general, tanto en sus desagües cuanto en las condiciones de ventilación e higienización de sus pisos" ${ }^{49}$. Un año después, en 1929, esta misma propietaria solicita los servicios de García-Nava para levantar un edificio ${ }^{50}$ de nueva construcción en la Plaza del Marqués de Salamanca, 11 en Madrid.

Entre la documentación existente en el archivo de la familia García-Nava encontramos un pequeño boceto de un panteón con anotaciones sobre materiales y precios (Fig. 5) y también un presupuesto dirigido a nuestro arquitecto sobre los gastos que supondría la ejecución de un panteón para la familia Cifuentes ${ }^{51}$ Fernández en el Cementerio de Ceares (Gijón). Hemos localizado en este cementerio un panteón a nombre de Julián Cifuentes y familia que

\footnotetext{
AMG. Expediente 3/1928. Memoria descriptiva.

50 AVM. Signatura 42-440-19.

51 Los descendientes de Julián Cifuentes no han podido verificar la autoría, porque la documentación se perdió durante la Guerra Civil.
} 

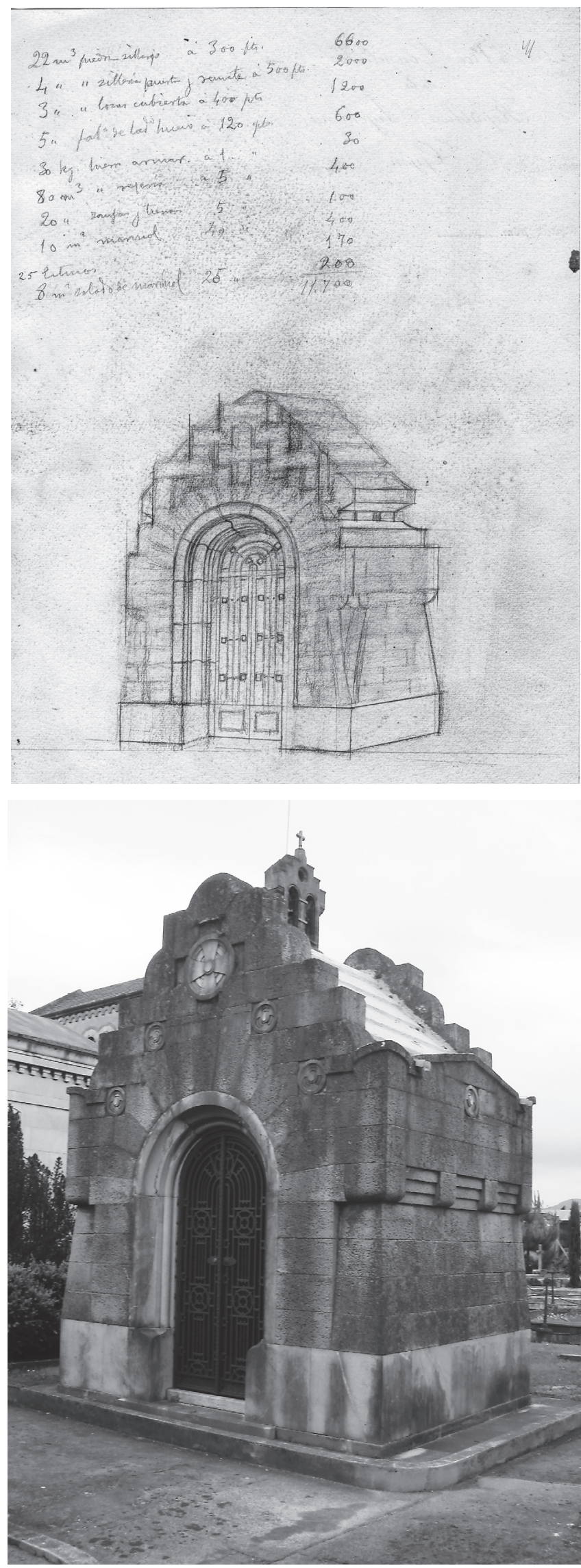

Fig. 5. Posible boceto del panteón de la familia Cifuentes en el cementerio de Ceares (Gijón). Fuente: Archivo de la familia García-Nava. 
concuerda con el boceto y el presupuesto mencionados (Fig. 6). La profesora Morales Saro lo describe, aunque no indica autor, sí ofrece una fecha $^{52}$, (1915). El Inventario del Patrimonio Arquitectónico de Asturias lo cataloga y define ${ }^{53}$ como ...

Monumento funerario de planta cuadrada sobre basamento. Tiene formas macizas en estructura de cruz griega. Las fachadas anterior y posterior tienen remate escalonado, combinando esquinas rectas y curvas. Puerta de arco de medio punto abocinada hacia el exterior con arquivoltas que alternan molduras cóncavas y convexas. El arco se rodea de falsas dovelas formando un dibujo escalonado, sobre el que se apoyan los adornos de placas de cruz griega inscrita en círculos, con una de mayor formato en el vértice superior. La fachada posterior repite la misma distribución, sustituyéndose la puerta por un vano circular cerrado con vidriera (...). Las fachadas laterales son de menor altura y sus muros ascienden en talud y se rematan con perfil triangular. La cubierta exterior es a doble vertiente escalonada en bandas (...).

Tampoco el IPAA hace referencia al autor. Lo data a principios del siglo XX. Si nos guiamos por la fecha del presupuesto, nos llevaría hasta 1929.

\section{Conclusiones}

A lo largo de los apartados anteriores se ha intentado clarificar algunos datos de la vida y obra de Francisco García Nava, incluyendo también información inédita. No hemos considerado su obra madrileña, porque hubiese excedido enormemente el espacio fijado para el presente trabajo. Además, ya se ha tratado por otros estudiosos.

Creemos que queda probada no sólo la amistad entre García Nava y Fernández- Peña, sino también su colaboración.

De convicciones conservadoras y profundamente religioso fue objeto de hostigamiento por parte de dos concejales del partido socialista, anteriormente comentado. A pesar de esto, continuó trabajando sin desanimarse.

52 MORALES SARO, $\mathrm{M}^{\mathrm{a}}$ Cruz.: El Modernismo en Asturias, opus cit., p. 93

53 IPAA, ficha G-200.
El acoso político lo padecieron infinidad de artistas de toda índole. Nos viene a la memoria el caso del también arquitecto municipal en el Ayuntamiento de Madrid y compañero suyo, Jesús Carrasco-Muñoz y Encina (1869-1957). "La República le relegó en su cometido de arquitecto municipal quitándole incluso el sueldo por desafecto al régimen (...) y el régimen franquista le jubiló anticipadamente, seguramente en este caso por no ser afecto al régimen." ${ }^{54}$

\section{Bibliografía}

Además de las citas bibliográficas:

- AA.VV.: Arquitectura de Madrid: casco histórico y ensanches. Fundación COAM, Madrid, 2003, (3 vols. y DVD).

- AA.VV.: Arquitectura de Madrid: periferia. Fundación COAM, Madrid, 2007.

- ALONSO PEREIRA, José Ramón.: “La ciudad burguesa de Oviedo y su plan especial”, en Liño. Revista anual de historia del arte, $\mathrm{n}^{\circ} 1$, Oviedo, 1980, pp. 99-105.

- BARROSO VILLAR, Julia.: "La arquitectura de valor histórico y artístico de la ciudad de Oviedo" en Liño. Revista anual de historia del arte, no 2, Oviedo, 1981, pp. 7-53.

- BERMEJO LORENZO, Carmen.: "El cementerio de Ceares en Gijón”, en Scripta: estudios en homenaje a Élida García García, Universidad de Oviedo, 1998, pp. 761-778.

- BLANCO GONZÁLEZ, Héctor.: Arquitectura sin arquitectos en Asturias. Maestros de obras y otros autores (1800-1935). Edita Consejería de Educación, Cultura y Deporte y Sistemas Gráficos Europa, Asturias, 2013.

- CHAO ARANA, Francisco Javier.: La arquitectura modernista en Asturias. Editorial Sedes, Oviedo, 2005.

- LLORDÉN MIÑAMBRES, Moisés.: "La arquitectura urbana de Gijón”, en Liño. Revista anual de historia del arte, $\mathrm{n}^{\circ} 2$, Oviedo, 1981, pp. 55-98.

- MADRID ÁlVAREZ, Vidal de la.: "Noticias sobre las obras de los arquitectos Manuel del Busto y Miguel de la Guardia en Avilés”, en Liño. Revista anual de historia del arte, $\mathrm{n}^{\circ} 8$, Oviedo, 1989, pp. 129-146.

54 ROCHA ARANDA, Óscar da y TORRRES NEIRA, Susana de.: Arquitectura madrileña. Del Eclecticismo a la Modernidad. Jesús Carrasco-Muñoz (1869-1957). Ediciones La Librería, Madrid, 2002, pp. 14-15. 
- MARÍN VALDÉS, Fernando Arturo.: "Avilés, ciudad y concejo", en Liño. Revista anual de historia del arte, $\mathrm{n}^{\circ}$ 2, Oviedo, 1981, pp. 99-129.

- MORALES SARO, Ma Cruz.: Oviedo-Arquitectura y Desarrollo Urbano. Del Eclecticismo al Movimiento Moderno. Ethos Arte, Oviedo, 1981.

- MORALES SARO, Ma Cruz.: "Pórticos, portales, balcones y cornisas. La secuencia modernista de la calle San Francisco de Avilés", en Sulcum sevit: Estudios en homenaje a Eloy Benito Ruano, volumen 2, Universidad de Oviedo, Oviedo, 2004, pp. 701-737.
- ROCHA ARANDA, Óscar da y MUÑOZ FAJARDO, Ricardo.: Madrid modernista: guía de arquitectura. Ed. Tébar-CSIC., Madrid, 2006.

- SAGUAR QUER, Carlos.: "Arquitectura modernista en los cementerios de Madrid", en Goya, no 217-218, julio-octubre, 1990, pp. 65-77.

- SAGUAR QUER, Carlos.: La arquitectura de la Necrópolis del Este. Ciclo de conferencias sobre el Madrid de Alfonso XIII. Artes Gráficas Municipales, Madrid, 1998. 